\title{
Research Article \\ Properties Enhancement of PS Nanocomposites through the POSS Surfactants
}

\author{
Huei-Kuan Fu, ${ }^{1}$ Shiao-Wei Kuo, ${ }^{2}$ Ding-Ru Yeh, ${ }^{1}$ and Feng-Chih Chang ${ }^{1}$ \\ ${ }^{1}$ Institute of Applied Chemistry, National Chiao-Tung University, Hsinchu 300, Taiwan \\ ${ }^{2}$ Center for Nanoscience and Nanotechnology, Department of Materials Science and Optoelectronic Engineering, \\ National Sun Yat-Sen University, Kaohsiung, 804, Taiwan \\ Correspondence should be addressed to Shiao-Wei Kuo, kuosw@faculty.nsysu.edu.tw \\ Received 5 August 2007; Accepted 5 February 2008 \\ Recommended by Junlan Wang
}

Polyhedral oligomeric silsesquioxane (POSS)-clay hybrids of polystyrene are prepared by two organically modified clays using POSS- $\mathrm{NH}_{2}$ and $\mathrm{C}_{20}$-POSS as intercalated agents. X-ray diffraction (XRD) studies show the formation of these POSS/clay/PS nanocomposites in all cases with the disappearance of the peaks corresponding to the basal spacing of MMT. Transmission electronic microscopy (TEM) was used to investigate the morphology of these nanocomposites and indicates that these nanocomposites are composed of a random dispersion of exfoliated clay platelets throughout the PS matrix. Incorporation of these exfoliated clay platelets into the PS matrix led to effectively increase in glass transition temperature $\left(T_{g}\right)$, thermal decomposition temperature $\left(T_{d}\right)$, and the maximum reduction in coefficient of thermal expansion (CTE) is ca. $40 \%$ for the $\mathrm{C}_{20}$-POSS/clay nanocomposite.

Copyright (c) 2008 Huei-Kuan Fu et al. This is an open access article distributed under the Creative Commons Attribution License, which permits unrestricted use, distribution, and reproduction in any medium, provided the original work is properly cited.

\section{INTRODUCTION}

Organic-inorganic hybrid materials are recognized as a new class of advanced material because they can be synthesized or processed using versatile approaches and own tunable properties $[1,2]$. Clays have been extensively used as reinforcement agents to prepare polymer-layered silicate nanocomposites with improved thermal and mechanical properties [3-9]. The incorporation of clay into polymer matrix imparts unique physical and chemical properties was first reported by the Toyota Research Lab for Nylon 6/organoclay nanocomposites [10]. These improvements are related to the dispersion of the layered silicate in the polymer matrix. Typically, the chemical structure of montmorillonite (MMT) consists of two fused silica tetrahedral sheets sandwiching an edge-shared octahedral sheet of either magnesium or aluminum hydroxide. Generally, the naturally occurring clays are hydrophilic characters and require a modification by intercalating with amino acid, alkylammonium, or phosphonium salts to become organically compatible $[11,12]$. The resulting organophilic galleries of the organically modified montmorillonite (OMMT) will enhance the compatibility with polymer [13]. Several methods to make polymer clay nanocomposites have been demonstrated, including solution mixing, melt blending, and in situ polymerization [14-16]. The interaction of layered silicates with polymers leads to two classes of hybrid materials. In the first class, denoted as intercalated hybrids, one or more polymer chains are inserted between the host layers, generating ordered lamella with the distance of a few nanometers. In the second, described as delaminated hybrids, silicate layers of $1 \mathrm{~nm}$ thickness are exfoliated and dispersed in the polymer matrix.

Polyhedral oligomeric silsesquioxane (POSS) reagents, monomers, and polymers are emerging as new chemical feedstocks for the preparation of organic-inorganic nanocomposites [17-21]. Silsesquioxane is the term for all structures with the formula $\left(\mathrm{RSiO}_{1.5}\right)_{n}$, where $\mathrm{R}$ is hydrogen or any alkyl, alkylene, aryl, arylene, or organic functional derivative groups. POSS compounds with diameters of 1$3 \mathrm{~nm}$ can be possibly considered the smallest particles of silica, but unlike silica, silicones, or fillers, POSS molecules contain either functionalized or unfunctionalized substituents at each of the corner silicon atoms. These substituents can compatibilize POSS molecules with polymers or monomers. POSS macromonomer and POSS-containing polymers inspires to prepare the functionalized POSS cages, which can be used as the intercalating agents of layered silicates to prepare the nanocomposites combining the two types of 

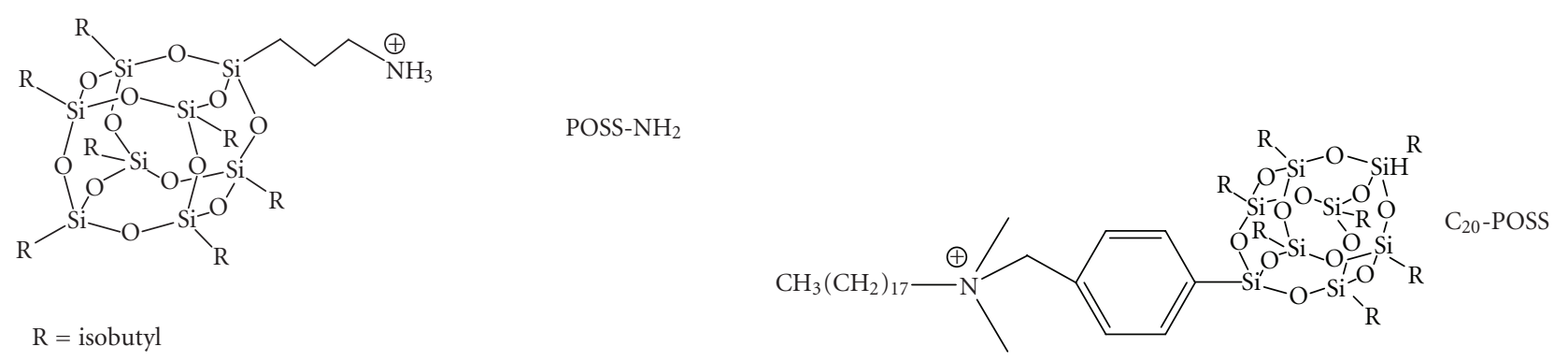

SCHeme 1: Chemical structures of the intercalated agents used to prepare the modified clays.
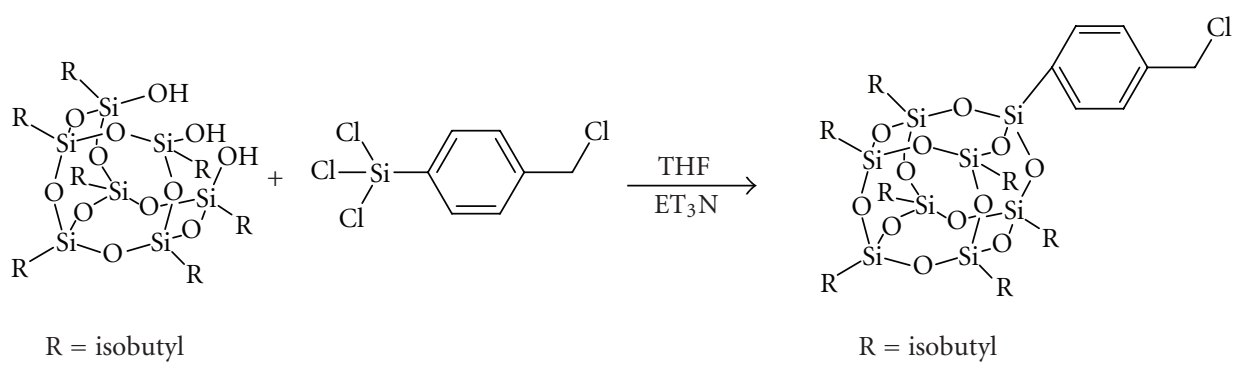

Scheme 2: Synthesis of POSS-Cl compound.

nanoreinforcement agents and improved mechanical and thermal properties.

In this study, these nanocomposites were prepared by emulsion polymerization using the POSS- $\mathrm{NH}_{2}$ and $\mathrm{C}_{20^{-}}$POSS-treated clays as shown in Scheme 1. The morphology and the extent of delamination of the nanocomposites are elucidated using the X-ray diffraction and transmission electron microscopy. The thermal properties of these nanocomposites are characterized by thermalgravimetric analysis and differential scanning calorimetry. The coefficient of thermal expansion of virgin PS and nanocomposites are measured by thermal mechanical analyzer.

\section{EXPERIMENTAL}

\subsection{Materials}

The sodium montmorillonite $\left(\mathrm{Na}^{+}-\mathrm{MMT}\right)$ with 1.45 mequiv/g cationic exchange capacity (CEC) was provided by Nanocor Co. (Ill, USA). The majority of chemicals used in this study including, acetone, methanol, tetrahydrofuran, acetonitrile, potassium hydroxide $(\mathrm{KOH})$, triethylamine, and trichloro [4-(chloromethyl)phenyl] silane were acquired from Sigma-Aldrich Chemical Co., Inc. The styrene monomer was purchased from Sigma-Aldrich Chemical Co. and purified by removing the inhibitor with the aid of an inhibitor-removal column. Sodium dodecyl sulfate (SDS) and hydrochloride acid $(\mathrm{HCl})$ were both obtained from Curtin Matheson Scientific, Inc. (Tex, USA). Potassium persulfate $\left(\mathrm{K}_{2} \mathrm{~S}_{2} \mathrm{O}_{8}\right)$ and aluminum sulfate $\left[\mathrm{Al}_{2}\left(\mathrm{SO}_{4}\right)_{3}\right]$ were acquired from Fisher Scientific, Inc. (Pittsburgh, USA). N,
$\mathrm{N}$-dimethyloctadecylamine $\left(\mathrm{C}_{20}\right)$ was obtained from Acros Organics, (NJ, USA). Trisilanolisobutyl polyhedral oligomeric silsesquioxane (T7-POSS) and aminopropylisobutyl polyhedral oligomeric silsesquioxane (POSS- $\mathrm{NH}_{2}$ ) were obtained from Hybrid Plastic Corporate Headquarters Inc. (USA). All reagents, except styrene, were used as received without further purification.

\subsection{Preparation of $C_{20}$-POSS intercalated agent}

The POSS-Cl compound was prepared by the method based on Scheme 2 [22]. Trisilanolisobutyl polyhedral oligomeric silsesquioxane $(3 \mathrm{~g})$ and $\mathrm{Et}_{3} \mathrm{~N}(1.26 \mathrm{~g})$ were added into a $100 \mathrm{~mL}$ two-neck round bottom flask and stirred continuously for 3 hours under nitrogen, then $20 \mathrm{~mL}$ of THF was added into the flask at $0^{\circ} \mathrm{C}$ for 1 hour. After stirring at $0^{\circ} \mathrm{C}$ under nitrogen, triethylamine, and trichloro[4(chloromethyl) phenyl] silane $(1.28 \mathrm{~g})$ in THF $(10 \mathrm{~mL})$ were added dropwisely into the solution and stirred at $0^{\circ} \mathrm{C}$. The cooling bath was removed and stirred continuously for 7.5 hours under nitrogen. The POSS-Cl compound and $\mathrm{HNEt}_{3}-$ $\mathrm{Cl}$ byproduct were separated by filtration. The clear THF solution was dropped into a beaker of acetonitrile and rapidly stirred. The resulting product was collected and dried in a vacuum oven for 24 hours. ${ }^{1} \mathrm{H}$ NMR (i.e., proton-NMR spectroscopy) $\left(\mathrm{CDCl}_{3}\right), \delta: 7.59(\mathrm{~d}, 2 \mathrm{H}), 7.33(\mathrm{~d}, 2 \mathrm{H}), 4.52(\mathrm{~s}, 2 \mathrm{H})$, $1.92-1.62(\mathrm{~m}, 7 \mathrm{H}), 1.09-0.85(\mathrm{~m}, 42 \mathrm{H}), 0.75-0.48(\mathrm{~m}, 14 \mathrm{H})$.

The intercalated agent of $\mathrm{C}_{20}$-POSS was prepared as shown in Scheme 2. N, N-dimethyloctadecylamine $\left(\mathrm{C}_{20}\right.$, $1.49 \mathrm{~g})$ and POSS-Cl compound $(5.68 \mathrm{~g})$ in acetone $(15 \mathrm{~mL})$ were refluxed $80^{\circ} \mathrm{C}$ under nitrogen for 24 hours. After 


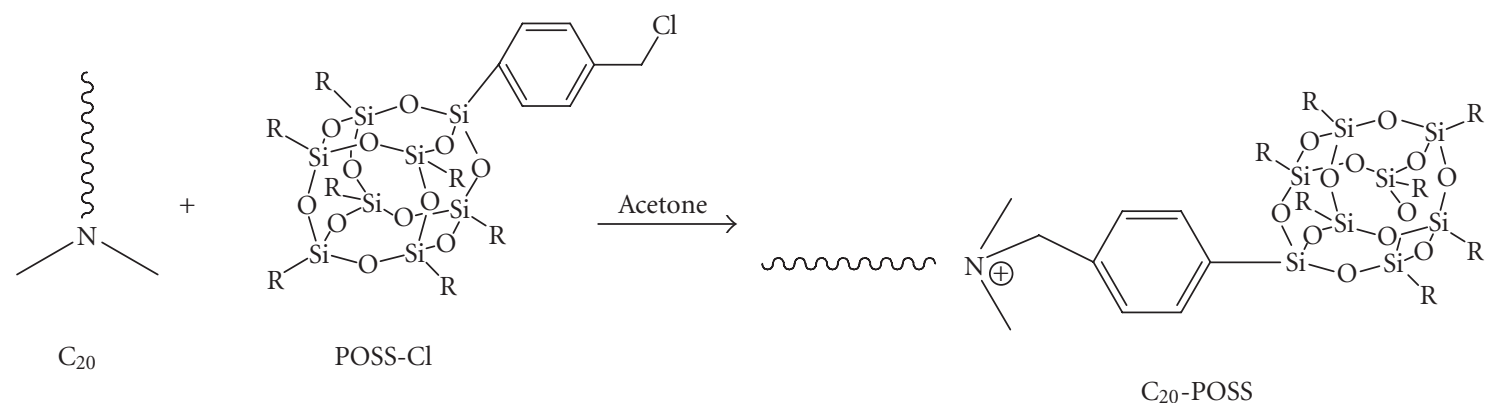

Scheme 3: Synthesis of the $\mathrm{C}_{20}$-POSS intercalated agent.

cooling, the mixture was evaporated by a rotatory evaporator and then added $\mathrm{Et}_{2} \mathrm{O}(20 \mathrm{~mL})$. The solution was extracted with deionized water three times $(150 \mathrm{~mL} \times 3)$. The organic phase was dried with $\mathrm{MgSO}_{4}$ and evaporated by arotatory evaporator to obtain the $\mathrm{C}_{20}$-POSS intercalated agent. ${ }^{1} \mathrm{H} \operatorname{NMR}\left(\mathrm{CDCl}_{3}\right), \delta: 7.68(\mathrm{~d}, 2 \mathrm{H}), 7.58(\mathrm{~d}, 2 \mathrm{H}), 5.03(\mathrm{~s}, 2 \mathrm{H})$, $3.42(\mathrm{t}, 2 \mathrm{H}), 3.30(\mathrm{~s}, 6 \mathrm{H}), 1.81(\mathrm{~m}, 7 \mathrm{H}), 1.41(\mathrm{~m}, 2 \mathrm{H}), 1.26$ $(\mathrm{m}, 30 \mathrm{H}), 0.90(\mathrm{~m}, 42 \mathrm{H}), 0.82(\mathrm{t}, 3 \mathrm{H}), 0.59(\mathrm{~m}, 14 \mathrm{H})$.

\subsection{Preparation of POSS-NH $\mathrm{H}_{2}$ and $\mathrm{C}_{20}$-POSS Modified Clays}

$\mathrm{Na}^{+} \mathrm{MMT}(0.3 \mathrm{~g})$ in deionized water $(50 \mathrm{~mL})$ was stirred continuously at $80^{\circ} \mathrm{C}$ for 4 hours. The POSS- $\mathrm{NH}_{2}(0.38 \mathrm{~g})$ or $\mathrm{C}_{20^{-}}$ POSS $(0.63 \mathrm{~g})$ in water $(5 \mathrm{~mL})$ was placed into another flask and then $10 \%$ hydrochloric acid $(1 \mathrm{~mL})$ and ethanol $(5 \mathrm{~mL})$ were added and stirred at $80^{\circ} \mathrm{C}$ for 1 hour. This intercalated solution was poured slowly into the clay suspension solution and stirred vigorously at $80^{\circ} \mathrm{C}$ for 4 hours. The resulting white precipitate was separated by filtration and then washed thoroughly with warm deionized water. The final product was dried in a vacuum oven at room temperature overnight.

\subsection{Preparation of Polystyrene/Clay Nanocomposites}

$\mathrm{Na}^{+}$-MMT $(0.3 \mathrm{~g})$ was dispersed in $40 \mathrm{~mL}$ of deionized water and stirred at $80^{\circ} \mathrm{C}$ for 4 hours. Based on the CEC value (145mequiv/100g) of the $\mathrm{Na}^{+}-\mathrm{MMT}$ and the $\mathrm{Mw}$ of the intercalated agent, the calculated weight (the weight of the intercalated agent needed to fully replace the $\mathrm{Na}^{+}$of the clay) of the intercalated agent was added and stirred for 4 hours. $\mathrm{KOH}$ $(0.02 \mathrm{~g})$, SDS $(0.4 \mathrm{~g}), \mathrm{K}_{2} \mathrm{~S}_{2} \mathrm{O}_{8}(0.05 \mathrm{~g})$, and styrene monomer $(10 \mathrm{~g})$ were added into the solution. After emulsification, the dispersion was flushed with nitrogen for 30 minutes while the temperature was raised to $80^{\circ} \mathrm{C}$ under nitrogen protection. Polymerization was carried out at $80^{\circ} \mathrm{C}$ for 8 hours. After cooling, $10 \mathrm{~mL}$ of the $2.5 \%$ aqueous aluminum sulfate was added into the polymerized emulsion, followed by dilute hydrochloric acid $(10 \mathrm{~mL})$ with stirring. Finally, acetone was added to break down the emulsion completely and then the polymer product was washed several times with methanol and deionized water. The white powder was filtered and dried in a vacuum oven at $80^{\circ} \mathrm{C}$ for 24 hours. Similar procedures were employed to prepare the virgin polystyrene.

\subsection{Instrumentations}

\subsubsection{Measurement of the molecular weights characterization}

Molecular weight $(\mathrm{Mw})$, number-average(Mn) molecular weight, and polydispersity index $(\mathrm{Mw} / \mathrm{Mn})$ were measured using a Waters 410 gel permeation chromatography (GPC) system equipped with RI and UV detectors and a series of styragel columns $\left(100,500\right.$, and $\left.10^{3} \AA\right)$. The system was calibrated using polystyrene standards. These polymer chains were extracted from the clay surface using a reverse ion exchange reaction with $\mathrm{LiCl} / \mathrm{DMF}$ to determine the molecular weight and molecular weight distribution.

\subsubsection{Structure analysis characterization}

${ }^{1} \mathrm{H}$ NMR spectra were recoded in $\mathrm{CDCl}_{3}$ on a Bruker $\mathrm{AM}$ $500(500 \mathrm{MHz})$ spectrometer using the solvent signal as an internal standard. FT-IR spectra were recorded using a Nicolet Avatar 320 FT-IR spectrometer; 32 scans were collected at a spectral resolution of $1 \mathrm{~cm}^{-1}$. The modified clay was mixed with $\mathrm{KBr}$ pellets to press into the small flakes and dried at $70^{\circ} \mathrm{C}$ for 24 hours. The holder was placed in the sample chamber and spectrum was recorded under $\mathrm{N}_{2}$ purge to maintain the test of the sample dryness.

Transmission electron microscopy (TEM) images were obtained on a Hitachi H-7500 operating at $100 \mathrm{kV}$. The sample was thin section to $\sim 70 \mathrm{~nm}$ by a Leica ultracut UCT microtome. Wide-angle X-ray diffraction (WAXD) experiments were carried on a Rigaku D/max-2500 type X-ray diffraction instrument with $\mathrm{Cu} \mathrm{K} \alpha$ radiation $(\lambda=1.54 \AA)$ using an Ni-filter. Data were recorded in the range of $2 \theta=1$ to 20 at the scanning rate of $0.6^{\circ} / \mathrm{min}$.

\subsubsection{Thermal and mechanical analysis characterization}

Thermal stability of nanocomposite was investigated by a TA Instruments Q50 apparatus. The sample $\sim 5 \mathrm{mg}$ was placed in a Pt cell with scan rate of $20^{\circ} \mathrm{C} / \mathrm{min}$ from 30 to $800^{\circ} \mathrm{C}$ under a $40 \mathrm{~mL} / \mathrm{min}$ flow of nitrogen gas. Thermal analysis through differential scanning calorimetry (DSC) was performed using a Du-Pont (DSC-2010) to measure the glass transition temperature $\left(T_{g}\right)$ of the nanocomposite. The sample was preheated at a scan rate of $20^{\circ} \mathrm{C} / \mathrm{min}$ from 30 to $150^{\circ} \mathrm{C}$ under 
a nitrogen atmosphere. A small sample (ca. 5-10 mg) was weighted and sealed in an aluminum pan. The sample was quickly cooled to $10^{\circ} \mathrm{C}$ from the first scan and then scanned between 30 and $150^{\circ} \mathrm{C}$ at the scan rate of $20^{\circ} \mathrm{C} / \mathrm{min}$. The glass transition temperatures are taken as the midpoint of the heat capacity transition between the upper and lower points of deviation from the extrapolated glass and liquid lines. The coefficient of thermal expansion (CTE) was measured using a thermomechanical analyzer (TMA TA 2940) by recording the change in dimension of the specimen with temperature. The specimen was heated from 25 to $150^{\circ} \mathrm{C}$ at a heating rate of $5^{\circ} \mathrm{C} / \mathrm{min}$.

\section{RESULTS AND DISCUSSION}

\subsection{Morphologies of modified clays and nanocomposites}

Microstructures of polymer-layered silicate nanocomposites were characterized by XRD and TEM. Figure 4 shows the $\mathrm{X}$-ray diffraction curves of the pristine clay and modified clays in the $2 \theta$ region of $2-10^{\circ}$. For the pristine clay, the Bragg diffraction peak at $2 \theta=6.92^{\circ}$ corresponds to $d$-spacing of $1.28 \mathrm{~nm}$. For the POSS- $\mathrm{NH}_{2} /$ clay and $\mathrm{C}_{20}$-POSS/clay, the $2 \theta$ value shifts from $6.92^{\circ}(1.28 \mathrm{~nm})$ to $5.51^{\circ}(1.61 \mathrm{~nm})$ and $2.33^{\circ}(3.80 \mathrm{~nm})$ after ion exchange, indicating that the basal spacing is expanded as the sodium cations in the interlayer galleries are replaced by intercalated agents of POSS- $\mathrm{NH}_{2}$ and $\mathrm{C}_{20}$-POSS. The increase of the basal spacing indicates that the clay can be efficiently intercalated by POSS- $\mathrm{NH}_{2}$ and $\mathrm{C}_{20}$-POSS. The $d$-spacing of the $\mathrm{C}_{20}$-POSS-modified clay is substantially greater than the POSS- $\mathrm{NH}_{2}$-modified clay. Larger interlayer spacing favors the penetration of styrene monomer and the formation of exfoliated nanocomposite by providing more hydrophobic environment. The pure POSS$\mathrm{NH}_{2}$ has characteristic diffraction peaks arising from the aggregation of the POSS [23]. Figure 5 shows XRD patterns of the unmodified clay and the $\mathrm{C}_{20}$-POSS modified clay. The pure $\mathrm{C}_{20}$-POSS has a broad peak in the region of $5-12^{\circ}$ arising from the $\mathrm{C}_{20}$ long aliphatic chain. When the $\mathrm{C}_{20}$-POSS is inserted between the galleries of the clay, the $d$ spacing is increased from $1.28 \mathrm{~nm}$ for original clay to $3.80 \mathrm{~nm}$, implying that the organic modifier is incorporated between and pushing the clay layers. Both nanocomposites do not show XRD diffraction peak as shown in Figure 6, indicating the silicate layers are exfoliated in the polymer matrix. TEM images for POSS- $\mathrm{NH}_{2}$ /clay and $\mathrm{C}_{20}$-POSS/clay nanocomposites at $3 \%$ inorganic clay loading are shown in Figures $7(\mathrm{a})$ and 7(b), indicating that the exfoliated clay platelets are distributed in the matrix homogeneously and randomly.

\subsection{Fourier transfer infrared analyses}

The representative FT-IR spectra of the organophilic clay, POSS- $\mathrm{NH}_{2}$-modified and $\mathrm{C}_{20}$-POSS modified clays are given in Figure 1. After ion exchange, FT-IR spectroscopy can provide important information regarding the difference between intercalated agents and modified clays. In Figure 1(a), characteristic vibration bands of the pure clay are $1030 \mathrm{~cm}^{-1}(\mathrm{Si}-$

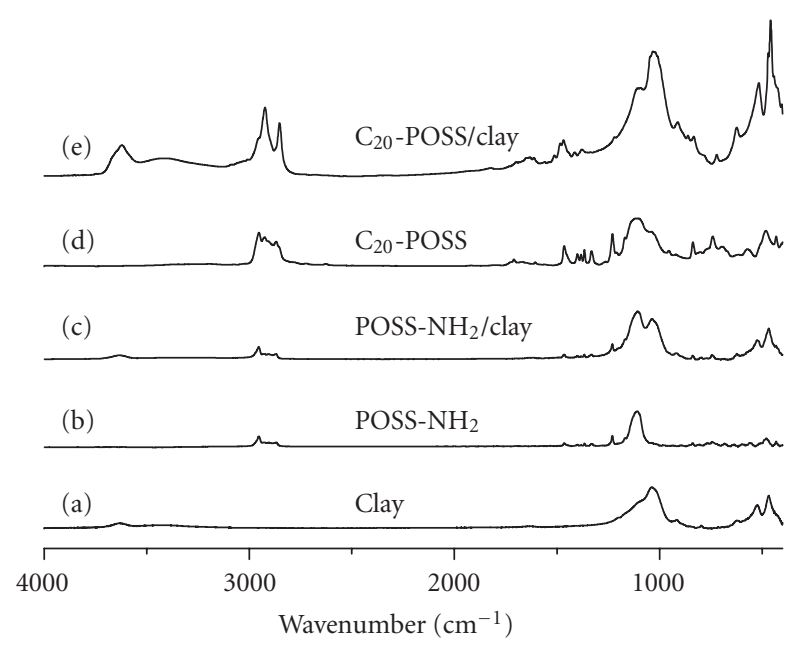

FIGURE 1: IR spectra of the two intercalated agent, intercalated clay, and pure clay.

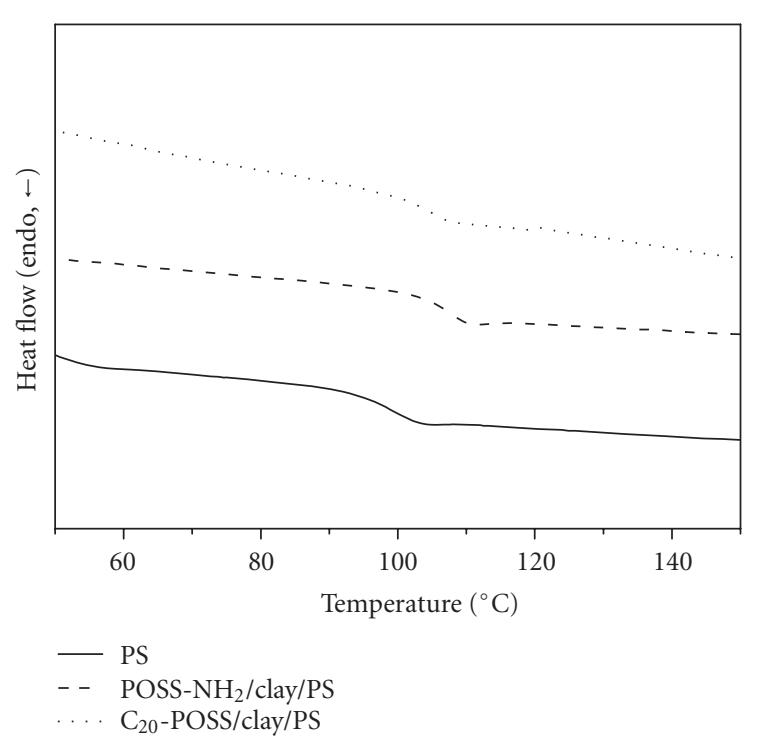

FIGURE 2: DSC curves glass transition temperature of (a) PS, (b) the nanocomposites formed used POSS- $\mathrm{NH}_{2}$, and (c) the nanocomposites formed used $\mathrm{C}_{20}$-POSS.

O), $520 \mathrm{~cm}^{-1}(\mathrm{Al}-\mathrm{O})$, and $470 \mathrm{~cm}^{-1}(\mathrm{Mg}-\mathrm{O})$ [24-26]. In Figure 1(b), the absorption peaks in the region of 2950-2800 is assigned to the stretching vibration of aliphatic $\mathrm{C}-\mathrm{H}$. The symmetrical Si-O-Si band in the silsequioxane cage is characterized by the stretching band at $1109 \mathrm{~cm}^{-1}$. In Figure 1(d), $\mathrm{C}_{20}$-POSS contains both alkyl chain and POSS moiety where the POSS moiety exhibits characteristic absorption peaks at $2950-2800 \mathrm{~cm}^{-1}$ (C-H bonds), $1230 \mathrm{~cm}^{-1}$ ( $\mathrm{Si}-\mathrm{C}$ bonds), $1109 \mathrm{~cm}^{-1}$ ( $\mathrm{Si}-\mathrm{O}-\mathrm{Si}$ bonds of the cage structure). The characteristics of the vibration band of alkyl chain appear at 2920, 2850, and $1475 \mathrm{~cm}^{-1}$ (- $\mathrm{CH}_{2}$-vibration bands). Figures 1 (c) and 1 (e) show the features of combination of characteristic bands of pure clay, POSS- $\mathrm{NH}_{2}$, and $\mathrm{C}_{20}$-POSS. IR analysis further confirms the existence of these intercalated agents in 


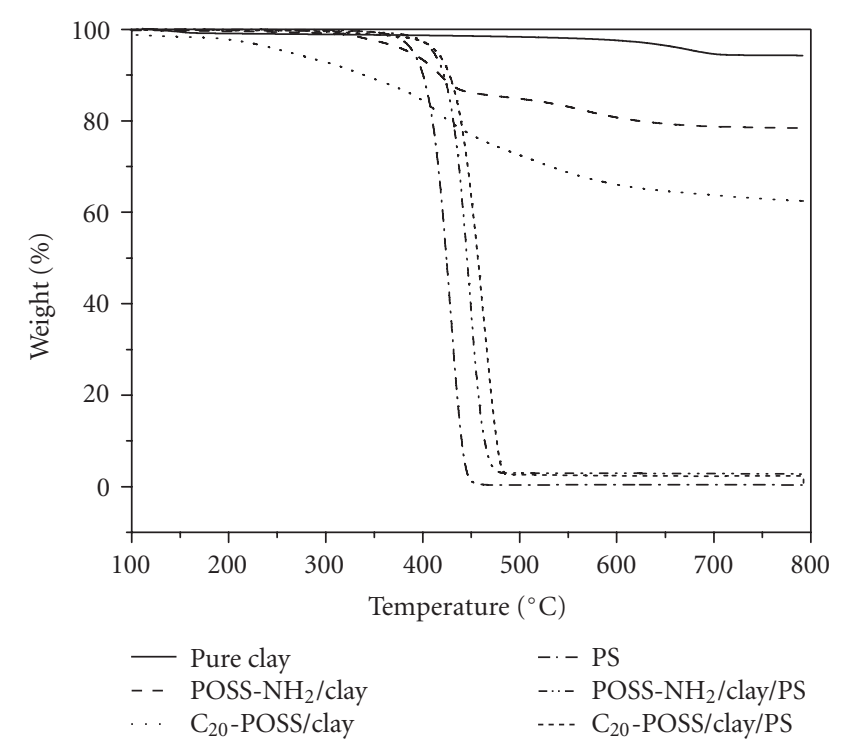

Figure 3: TGA curves of (a) pure Clay, (b) POSS- $\mathrm{NH}_{2} /$ Clay, (c) $\mathrm{C}_{20}$-POSS/Clay, (d) pure PS, (e) the nanocomposite formed with POSS- $\mathrm{NH}_{2}$, and (f) the nanocomposite formed with $\mathrm{C}_{20}$-POSS.

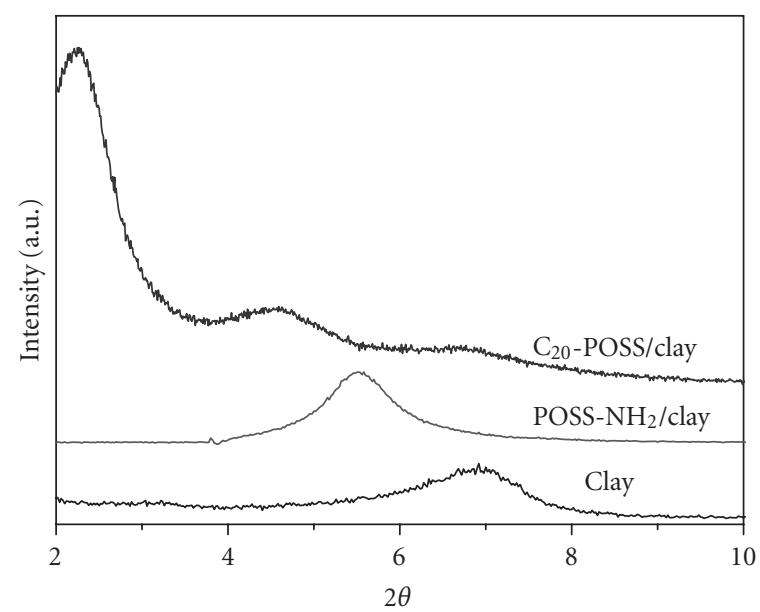

FIGURE 4: X-Ray diffraction patterns of pure clay, and intercalated clay.

these intercalated clay samples, implying that these intercalations of the intercalated agents are indeed present within the gallery gap. These observations support the explanation in the earlier observation from XRD.

\subsection{Thermal properties}

Figure 2 presents DSC traces of these nanocomposites with different intercalated agents. All DSC thermograms display single glass transition temperatures in the experimental temperature range. The glass transition temperature of PS occurs at $100^{\circ} \mathrm{C}$. With the addition of the POSS and $\mathrm{C}_{20}-$ POSS modified MMT to the polymer matrix, the glass transition temperatures $\left(T_{g} \mathrm{~s}\right)$ of the POSS- $\mathrm{NH}_{2} /$ clay/PS and $\mathrm{C}_{20^{-}}$

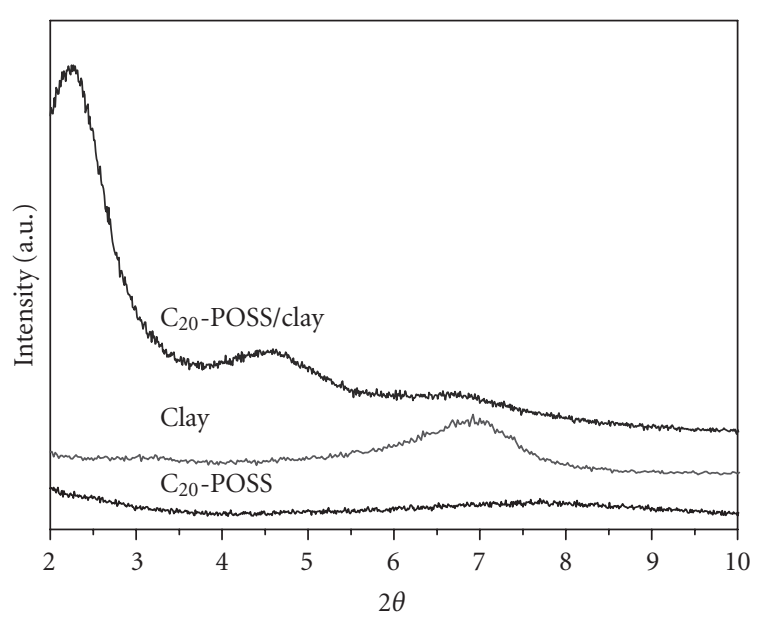

FIGURE 5: XRD spectra of $\mathrm{C}_{20}$-POSS, pure clay, and $\mathrm{C}_{20}$-POSS/Clay.

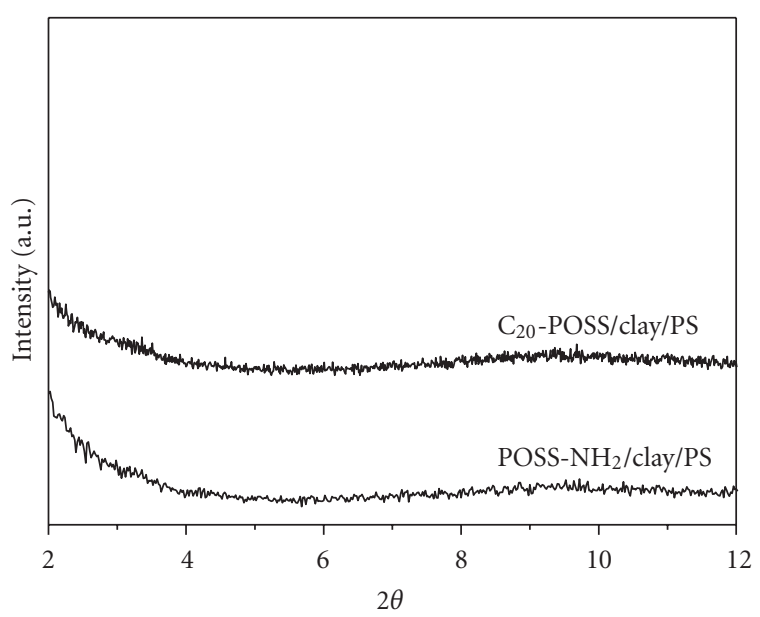

FIGURE 6: XRD spectra of the two surfactant-containing nanocomposites indicating the extent of delamination.

POSS/clay/PS are 108 , and $105^{\circ} \mathrm{C}$, respectively. From the DSC results that the incorporation of the organoclay resulted in an increase in the $T_{g}$ relative to virgin PS, as summarized in Table 1. The addition of clay results in $T_{g}$ increase which can be attributed to the retardation of PS chain movement.

Figure 3 presents the thermal stabilities of POSS- $\mathrm{NH}_{2}$ and $\mathrm{C}_{20}$-POSS-modified clays and nanocomposites investigated by TGA. Both nanocomposites show improved thermal stabilities than the virgin PS. The improvement in the degradation temperature is mainly due to the homogeneous dispersion of silicate nanoplatelets in the PS matrix [27-30]. In Figure 3, the $\mathrm{C}_{20}$-POSS/clay decomposes at $262^{\circ} \mathrm{C}$ while the POSS- $\mathrm{NH}_{2} /$ clay decomposes at higher temperature of $38^{\circ} \mathrm{C}$. The POSS- $\mathrm{NH}_{2}$-modified clay is relatively more stable than the $\mathrm{C}_{20}$-POSS-modified clay. Essentially, all nanocomposites give higher decomposition temperatures than the pristine PS and the improved thermal stability can be attributed to the diffusion hindrance of the decomposited volatiles. The values of $5 \%$ and $50 \%$ weight loss temperatures and the char yields are summarized in Table 1. 
TABLE 1: Results of thermal and mechanical properties of polystyrene and polystyrene nanocomposites.

\begin{tabular}{|c|c|c|c|c|c|}
\hline Sample & $T_{g},\left({ }^{\circ} \mathrm{C}\right)^{(\mathrm{a})}$ & $T_{0.05},\left({ }^{\circ} \mathrm{C}\right)^{(\mathrm{b})}$ & $T_{0.5},\left({ }^{\circ} \mathrm{C}\right)^{(\mathrm{c})}$ & Char at $600\left({ }^{\circ} \mathrm{C}\right) \%$ & $\mathrm{CTE}\left(\mu \mathrm{m} / \mathrm{m}^{\circ} \mathrm{C}\right)$ \\
\hline PS & $100 \pm 0.5$ & $390 \pm 1.7$ & $424 \pm 0.8$ & 0 & $164 \pm 2$ \\
\hline POSS/Clay/PS & $108 \pm 0.6$ & $411 \pm 1.3$ & $446 \pm 1.2$ & 2.9 & $98 \pm 1$ \\
\hline $\mathrm{C}_{20}-\mathrm{POSS} / \mathrm{Clay} / \mathrm{PS}$ & $105 \pm 0.3$ & $415 \pm 1.1$ & $457 \pm 0.9$ & 2.4 & $100 \pm 3$ \\
\hline
\end{tabular}

(a) Glass transition temperature $\left(T_{g}\right)$.

(b) $5 \%$ Degradation temperature $\left(T_{0.05}\right)$.

(c) $50 \%$ Degradation temperature $\left(T_{0.5}\right)$.

TABLE 2: Molecular weights of polystyrene and polystyrene nanocomposites.

\begin{tabular}{|c|c|c|c|}
\hline Sample & $\mathrm{Mn}\left(\times 10^{4}\right)^{(\mathrm{a})}$ & $\mathrm{Mw}\left(\times 10^{4}\right)^{(\mathrm{b})}$ & PDI $(\mathrm{Mw} / \mathrm{Mn})^{(\mathrm{c})}$ \\
\hline PS & 34.5 & 53.1 & 1.54 \\
\hline POSS- $\mathrm{NH}_{2} /$ Clay/PS & 40.9 & 54.0 & 1.32 \\
\hline $\mathrm{C}_{20}$-POSS/Clay/PS & 47.7 & 58.7 & 1.23 \\
\hline
\end{tabular}

${ }^{(a)}$ Number-average molecular weights (Mn).

(b) Weight-average molecular weights $(\mathrm{Mw})$ were determined by GPC.

(c) Polydispersity index, Mw/Mn.

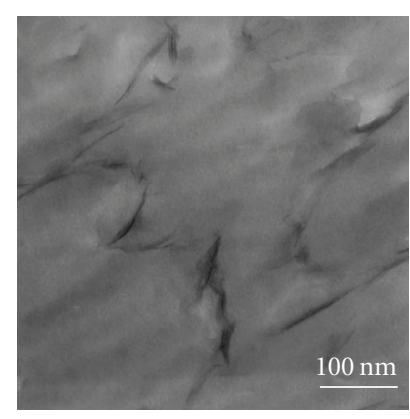

(a)

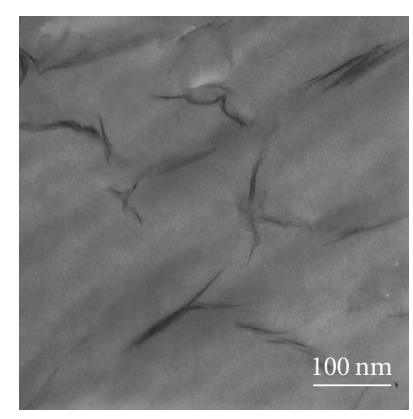

(b)
FIgure 7: TEM images of (a) POSS- $\mathrm{NH}_{2}$ and (b) $\mathrm{C}_{20}$-POSS-treated nanocomposites.

\subsection{Molecular weights of the nanocomposites}

Molecular weight and molecular weight distribution (PDI) by GPC analyses of polymer samples recovered after excluding all clay content are listed in Table 2. From Table 2, molecular weight (Mw or Mn) of the PS in the PS/clay nanocomposites is higher than the pure PS, suggesting that clay may act as a catalytic agent responsible for the observed higher molecular weight of the PS with the proceeding emulsion polymerization.

\subsection{Coefficient of thermal coefficient}

Thermal mechanical analyzer (TMA) was used to determine the coefficient of thermal expansion of the POSS/clay nanocomposites. The thermal expansion coefficient is an important issue for polymers in engineering applications. The CTE was measured from the initial linear slope of the thermal strain-temperature plot. A low thermal expansion coefficient is often desirable to achieve dimensional stability and can be achieved by incorporation of a rigid and low CTE filler material. From the data in Table 1, the CTE of the virgin PS is $164 \mu \mathrm{m} / \mathrm{m}^{\circ} \mathrm{C}$ and the addition $3 \mathrm{wt} \%$ organically modified clays reduces the CTE values to 98 and $100 \mu \mathrm{m} / \mathrm{m}^{\circ} \mathrm{C}$ for POSS/clay/PS and $\mathrm{C}_{20}$-POSS/clay/PS approximately $40 \%$ reduction relative to the virgin PS.

In general, the extent of CTE reduction depends on the particle rigidity and fine dispersion of the clay platelets in the PS matrix and also due to efficient stress transfer to clay layers. The retardation of PS chain segmental movement through incorporation of organically modified clays also leads to decrease in the coefficient of thermal expansion (CTE). The incorporation of the organically modified clays results in significant improvement in dimensional stability of the PS matrix.

\section{CONCLUSIONS}

The POSS-clay hybrids of polystyrene are prepared via emulsion polymerization using two organically modified clays, POSS- $\mathrm{NH}_{2}$ and $\mathrm{C}_{20}$-POSS, as intercalated agents. X-ray diffraction (XRD) results indicate that the clay is successfully intercalated by POSS- $\mathrm{NH}_{2}$ and $\mathrm{C}_{20}$-POSS. The random dispersion of these exfoliated silicate layers in these nanocomposites are identified by XRD and TEM. These well dispersed clay platelets in PS matrix result in improved thermal properties in terms of thermal decomposition temperature $\left(T_{d}\right)$ and glass transition temperature $\left(T_{g}\right)$. In addition, the incorporation of these organoclay results in significant reduction in coefficient of thermal expansion of virgin PS.

\section{ACKNOWLEDGMENT}

This work was financially supported by the National Science Council, Taiwan, under Contracts no. NSC-96-2120-M-009009 a nd NSC-96-2218-E-110-008. 


\section{REFERENCES}

[1] H.-A. Klok and S. Lecommandoux, "Supramolecular materials via block copolymer self-assembly," Advanced Materials, vol. 13, no. 16, pp. 1217-1229, 2001.

[2] C. Sanchez, G. J. de A. A. Soler-Illia, F. Ribot, T. Lalot, C. R. Mayer, and V. Cabuil, "Designed hybrid organicinorganic nanocomposites from functional nanobuilding blocks," Chemistry of Materials, vol. 13, no. 10, pp. 3061-3083, 2001.

[3] C. Park, J. G. Smith Jr., J. W. Connell, S. E. Lowther, D. C. Working, and E. J. Siochi, "Polyimide/silica hybrid-clay nanocomposites," Polymer, vol. 46, no. 23, pp. 9694-9701, 2005.

[4] D.-R. Yei, S.-W. Kuo, H.-K. Fu, and F.-C. Chang, "Enhanced thermal properties of PS nanocomposites formed from montmorillonite treated with a surfactant/cyclodextrin inclusion complex," Polymer, vol. 46, no. 3, pp. 741-750, 2005.

[5] W. Xie, J. M. Hwu, G. J. Jiang, T. M. Buthelezi, and W.-P. Pan, "A study of the effect of surfactants on the properties of polystyrene-montmorillonite nanocomposites," Polymer Engineering \& Science, vol. 43, no. 1, pp. 214-222, 2003.

[6] D.-R. Yei, S.-W. Kuo, Y.-C. Su, and F.-C. Chang, "Enhanced thermal properties of PS nanocomposites formed from inorganic POSS-treated montmorillonite," Polymer, vol. 45, no. 8 , pp. 2633-2640, 2004.

[7] C.-R. Tseng, J.-Y. Wu, H.-Y. Lee, and F.-C. Chang, "Preparation and characterization of polystyrene-clay nanocomposites by free-radical polymerization," Journal of Applied Polymer Science, vol. 85, no. 7, pp. 1370-1377, 2002.

[8] S. Su and C. A. Wilkie, "Exfoliated poly(methyl methacrylate) and polystyrene nanocomposites occur when the clay cation contains a vinyl monomer," Journal of Polymer Science A, vol. 41, no. 8, pp. 1124-1135, 2003.

[9] M. H. Kim, C. I. Park, W. M. Choi, et al., "Synthesis and material properties of syndiotactic polystyrene/organophilic clay nanocomposites," Journal of Applied Polymer Science, vol. 92, no. 4, pp. 2144-2150, 2004.

[10] A. Okado, M. Kawasumi, T. Kurauchi, and O. Kamigaito, "Synthesis and characterization of a nylon 6-clay hybrid," Polymer Preprints, vol. 28, pp. 447-448, 1987.

[11] D. Kong and C. E. Park, "Real time exfoliation behavior of clay layers in epoxy-clay nanocomposites," Chemistry of Materials, vol. 15, no. 2, pp. 419-424, 2003.

[12] W.-B. Xu, S.-P. Bao, and P.-S. He, "Intercalation and exfoliation behavior of epoxy resin/curing agent/montmorillonite nanocomposite," Journal of Applied Polymer Science, vol. 84, no. 4, pp. 842-849, 2002.

[13] A. Akelah, "Nanocomposites of grafted polymers onto layered silicates," in Polymers and Other Advanced Materials: Emerging Technologies and Business Opportunities, P. N. Prasad, J. E. Mark, and J. F. Tung, Eds., pp. 625-644, Plenum Press, New York, NY, USA, 1995.

[14] R. A. Vaia, S. Vasudevan, W. Krawiec, L. G. Scanlon, and E. P. Giannelis, "New polymer electrolyte nanocomposites: melt intercalation of poly(ethylene oxide) in mica-type silicates," Advanced Materials, vol. 7, no. 2, pp. 154-156, 1995.

[15] E. P. Giannelis, "Polymer layered silicate nanocomposites," Advanced Materials, vol. 8, no. 1, pp. 29-35, 1996.

[16] J. W. Gilman, A. B. Morgan, R. H. Harris, P. C. Trulove, H. C. Delong, and T. E Sutto, "Polymer layered silicate nanocomposites: thermal stability of organic cationic treatments," Polymeric Materials Science and Engineering, vol. 83, pp. 59-60, 2000 .
[17] J. D. Lichtenhan, N. Q. Vu, J. A. Carter, J. W. Gilman, and F. J. Feher, "Silsesquioxane-siloxane copolymers from polyhedral silsesquioxanes," Macromolecules, vol. 26, no. 8, pp. 21412142, 1993.

[18] J. D. Lichtenhan, Y. A. Otonari, and M. J. Carr, "Linear hybrid polymer building blocks: methacrylate-functionalized polyhedral oligomeric silsesquioxane monomers and polymers," Macromolecules, vol. 28, no. 24, pp. 8435-8437, 1995.

[19] T. S. Haddad and J. D. Lichtenhan, "The incorporation of transition metals into polyhedral oligosilsesquioxane polymers," Journal of Inorganic Organometallic Polymer, vol. 5, no. 3, pp. 237-246, 1995.

[20] R. A. Mantz, P. F. Jones, K. P. Chaffee, et al., "Thermolysis of polyhedral oligomeric silsesquioxane (POSS) macromers and POSS-siloxane copolymers," Chemistry of Materials, vol. 8, no. 6, pp. 1250-1259, 1996.

[21] T. S. Haddad and J. D. Lichtenhan, "Hybrid organicinorganic thermoplastics: styryl-based polyhedral oligomeric silsesquioxane polymers," Macromolecules, vol. 29, no. 22, pp. 7302-7304, 1996.

[22] C.-F. Huang, S.-W. Kuo, F.-J. Lin, et al., "Influence of PMMAchain-end tethered polyhedral oligomeric silsesquioxanes on the miscibility and specific interaction with phenolic blends," Macromolecules, vol. 39, no. 1, pp. 300-308, 2006.

[23] H. Zhang, C. Wang, M. Li, X. Ji, J. Zhang, and B. Yang, "Fluorescent nanocrystal-polymer composites from aqueous banocrystals: methods without ligand exchange," Chemistry of Materials, vol. 17, no. 19, pp. 4783-4788, 2005.

[24] J.-M. Yeh, S.-J. Liou, C.-Y. Lai, P.-C. Wu, and T.-Y. Tsai, "Enhancement of corrosion protection effect in polyaniline via the formation of polyaniline-clay nanocomposite materials," Chemistry of Materials, vol. 13, no. 3, pp. 1131-1136, 2001.

[25] J.-M. Yeh, S.-J. Liou, C.-Y. Lin, C.-Y. Cheng, Y.-W. Chang, and K. R. Lee, "Anticorrosively enhanced PMMA-clay nanocomposite materials with quaternary alkylphosphonium salt as an intercalating agent," Chemistry of Materials, vol. 14, no. 1, pp. 154-161, 2002.

[26] J.-M. Yeh, C.-L. Chen, Y.-C. Chen, et al., "Enhancement of corrosion protection effect of poly(o-ethoxyaniline) via the formation of poly(o-ethoxyaniline)-clay nanocomposite materials," Polymer, vol. 43, no. 9, pp. 2729-2736, 2002.

[27] P. Uthirakumar, K. S. Nahm, Y. B. Hahn, and Y.-S. Lee, "Preparation of polystyrene/montmorillonite nanocomposites using a new radical initiator-montmorillonite hybrid via in situ intercalative polymerization," European Polymer Journal, vol. 40, no. 11, pp. 2437-2444, 2004.

[28] T. K. Chen, Y. I. Tien, and K. H. Wei, "Synthesis and characterization of novel segmented polyurethane/clay nanocomposite

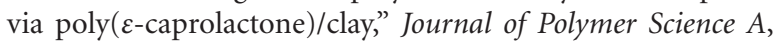
vol. 37, no. 13, pp. 2225-2233, 1999.

[29] J. G. Doh and I. Cho, "Synthesis and properties of polystyreneorganoammonium montmorillonite hybrid," Polymer Bulletin, vol. 41, no. 5, pp. 511-518, 1998.

[30] X. Fu and S. Qutubiddin, "Polymer-clay nanocomposites: exfoliation of organophilic montmorillonite nanolayers in polystyrene," Polymer, vol. 42, no. 2, pp. 807-813, 2001. 

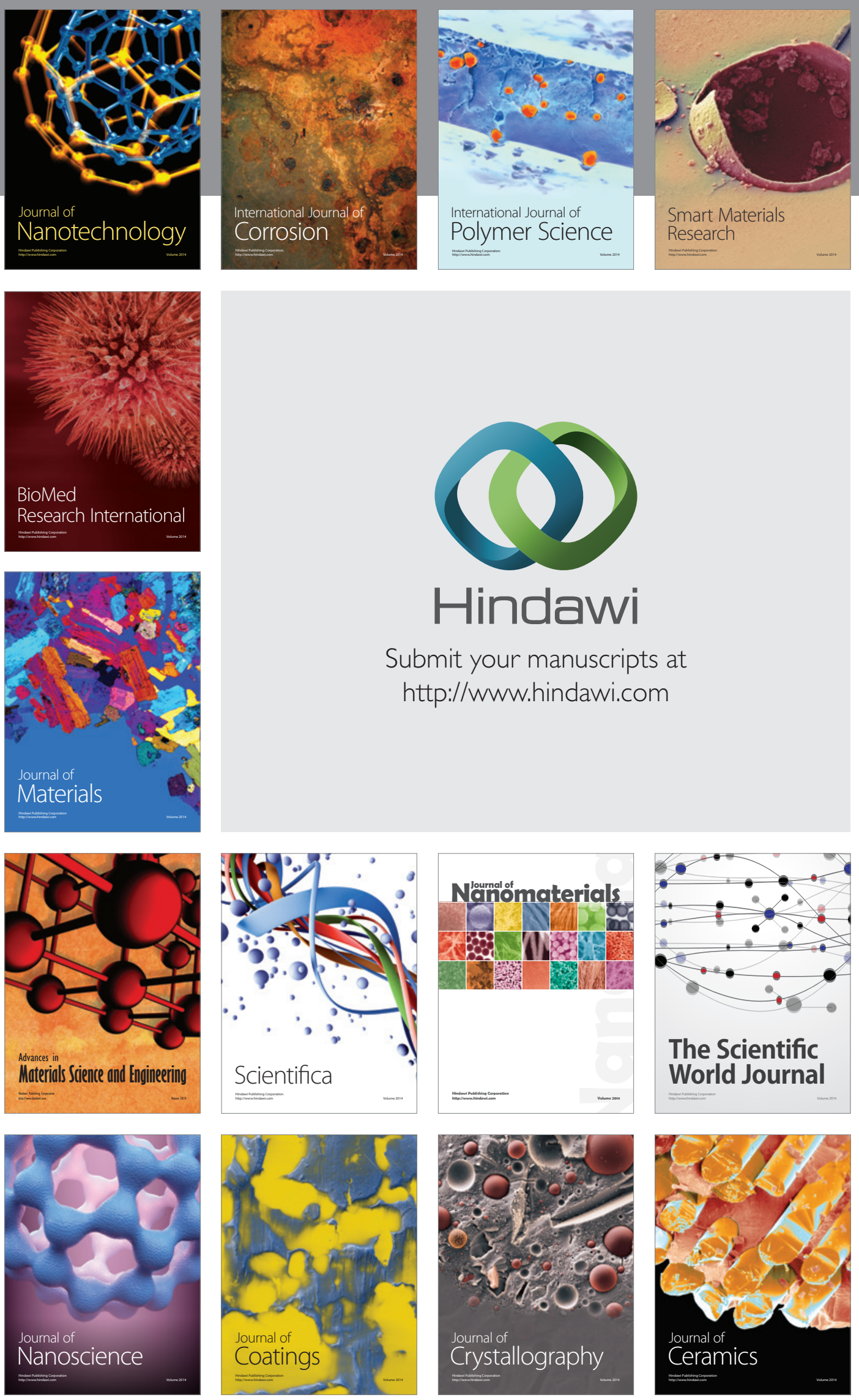

The Scientific World Journal

Submit your manuscripts at

http://www.hindawi.com

\section{World Journal}

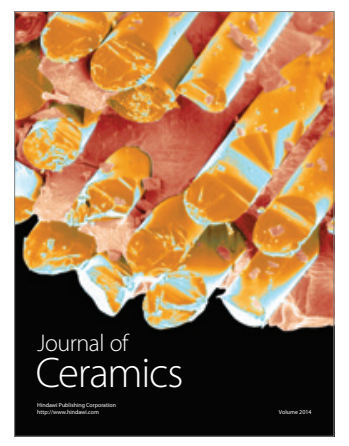

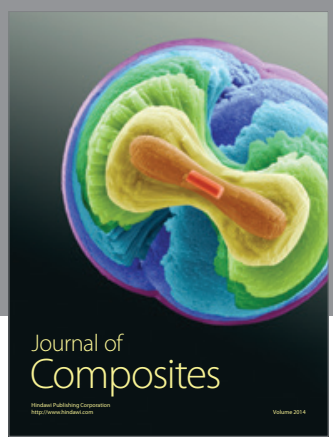
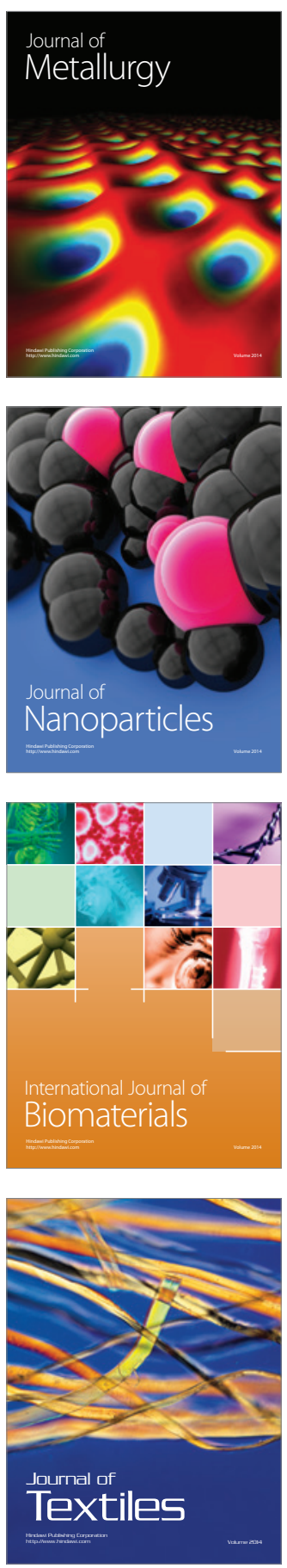